\title{
Apoptosis: Molecular mechanisms, regulation and role in pathogenesis
}

\author{
RYAN WEI YAN HUNG BSC, ANTHONY W CHOW MD FRCPC FACP
}

\begin{abstract}
RWY HUNG, AW CHOW. Apoptosis: Molecular mechanisms, regulation and role in pathogenesis. Can J Infect Dis 1997;8(2):103-109.

OBJECTIVE: To review the current state of knowledge of apoptosis, with an emphasis on identifying potential and established roles for apoptosis in the pathogenesis of infectious diseases.

DATA SOURCES: MEDLINE and the University of British Columbia library system were searched using the search subject, "apoptosis", for the years 1992 to 1996. Further search terms (eg, "pathogenesis") were used to narrow the results. These review articles and reference books were used as the basis for locating original articles on particular studies.

DATA SELECTION: Approximately 40 studies were reviewed, with the criterion for selection being the relevance to either the molecular mechanisms behind apoptosis or roles for apoptosis in the pathogenesis of infectious diseases. DATA EXTRACTION: Relevant information from each study was collated into categories specific to morphological and biochemical characterization, and the regulation and molecular mechanisms of apoptosis and its role in the pathogenesis of infectious diseases.

DATA SYNTHESIS AND CONCLUSIONS: Apoptosis is characterized by distinct morphological and biochemical changes that distinguish it from cell necrosis. Different signal transduction events and transcription factors can promote or inhibit apoptosis, although where and how these tie into the cell death pathway is still poorly understood. Apoptosis has been implicated in the pathogenesis of infectious diseases in two distinct ways: first, multicellular organisms use apoptosis to combat viral infections; and second, pathogens can alter the normal process of apoptosis in host cells by abnormal upregulation or downregulation. Many diseases have been shown to implicate apoptosis in their pathogenesis, raising the possibility of novel treatments for some disorders by therapeutically altering the occurrence and course of apoptosis. Therefore, further study of apoptosis in both health and disease needs to be rigorously pursued.
\end{abstract}

Key Words: Apoptosis, Cell death, Pathogenesis, Regulation

\section{Apoptose : mécanismes moléculaires, régulation et rôle dans la pathogenèse}

OBJECTIF : Passer en revue l'état actuel des connaissances sur l'apoptose en insistant sur l'identification des rôles potentiels et confirmés de l'apoptose dans la pathogenèse des maladies infectieuses.

SOURCE DES DONNÉES : On a effectué une recherche auprès du Réseau MEDLINE et du système des bibliothèques de l'Université de la Colombie-Britannique à partir du thème apoptose pour les années 1992 à 1996. D'autres mots clés (p. ex., pathogenèse) ont été utilisés pour réduire le champ de l'interrogation. Des articles de synthèse et des ouvrages de référence ont été utilisés comme base pour localiser les articles originaux portant sur des études particulières.

SÉLECTION DES DONNÉES : Environ 40 études ont été passées en revue à partir du critère de sélection suivant : pertinence des mécanismes moléculaires sous-jacents dans l'apoptose ou rôles de l'apoptose dans la pathogenèse des maladies infectieuses.

EXTRACTION DES DONNÉES : Les renseignements pertinents de chaque étude ont été classés par type de caractères

voir page suivante

Division of Infectious Diseases, Department of Medicine, University of British Columbia, Vancouver Hospital Health Sciences Center, Vancouver, British Columbia

Correspondence and reprints: Dr Anthony W Chow, Division of Infectious Diseases, GF Strong Research Laboratories, Vancouver Hospital Health Sciences Center, 2733 Heather Street, Vancouver, British Columbia V5Z 3J5. Telephone 604-875-4148, fax 604-875-4013,

e-mail tonychow@unixg.ubc.ca 
morphologiques et biochimiques et selon leur qu'ils concernaient la régulation et le mécanisme moléculaire de l'apoptose et son rôle dans la pathogenèse des maladies infectieuses.

SYNTHÈSE DES DONNÉES ET CONCLUSIONS : L'apoptose est caractérisée par des modifications morphologiques et biochimiques distinctes de celles de la nécrose cellulaire. Différentes étapes de la transduction des signaux et des facteurs de la transcription peuvent favoriser ou inhiber l'apoptose. Même si l'on comprend encore mal la localisation et le mécanisme de ces liens dans la mort cellulaire. L'apoptose a été associée à la pathogenèse des maladies infectieuses de deux façons : premièrement, les organismes multicellulaires utilisent l'apoptose pour combattre les infections virales et deuxièmement, les organismes pathogènes peuvent altérer le processus normal d'apoptose chez les cellules hôtes en influant à la hausse ou à la baisse sur la régulation. De nombreuses maladies se sont révélées associées à l'apoptose sur le plan de leur pathogenèse, soulevant la possibilité de nouveaux traitements pour certaines maladies par le truchement d'une modification thérapeutique de l'installation et de l'évolution de l'apoptose. Par conséquent, il faudra poursuivre énergiquement la recherche sur l'apoptose dans les états normaux et pathologiques.

F ive years ago, few biologists could have defined the term apoptosis. Today apoptosis, or programmed cell death, is recognized as so fundamentally important to almost all organisms that most researchers in the life sciences are familiar with it. Every week, new information is added to the mountain of research already published on apoptosis, with implications for a great number of fields: immunology, embryogenesis, oncology, pathogenesis and others (1). It is evident that a review of this scale cannot possibly cover in any depth the enormous body of data on apoptosis; nor is this review intended to be all inclusive. Rather, only succinct summaries of the most important and relevant topics of apoptosis are presented, with a particular emphasis on its role in the pathogenesis of infectious diseases.

Apoptosis is not a new discovery - it can be traced to the 1970s when pathologists first described apoptosis as being a morphologically distinct process from necrosis, the other major form of cell death. However, after the initial characterization in 1972 (2), the scientific community set apoptosis on the backburner for almost 10 years. There were several reasons for this apparent lack of interest. First, while most biologists knew that cells had to die naturally for a multicellular organism to maintain homeostasis, few could fathom why learning the exact mechanisms of cell death would be important. Second, cell death in itself seemed somewhat counter-intuitive: why should multicellular organisms expend the luxury of wasting cells? Many believed cell death to be a relatively uncommon process, associated more with unusual or abnormal circumstances than with normalcy. Finally, apoptosis itself, by virtue of its morphology and quickness of completion, was difficult to observe directly. Hence, pathologists studying cells in the light microscope for half a century failed to notice apoptotic cells.

In the 10 year hiatus from the initial characterization to the next major developments in apoptosis research, many scientists considered it to be a relatively rare process in organisms. In fact, for another 10 years after this, the scientific validity of apoptosis, in terms of whether it existed and what its importance was, engendered considerable controversy.

\section{CHARACTERIZATION}

The first characteristics of apoptosis identified were morphological (3). The term apoptosis is derived from Greek to describe its morphological features, meaning 'falling off', in reference to leaves falling off a tree. Apoptosis usually affects individual, scattered cells, making it difficult to observe by light microscopy, even though a large number of cells may be dying as in embryogenesis.

Under the light microscope, one observes two phases of apoptosis. First, an apoptotic cell forms apoptotic bodies, small membrane-bound fragments of the original cell. Second, the apoptotic bodies are rapidly phagocytized by surrounding cells, either neighbouring cells or by macrophages (4). In the initial stage, the first visible indication of apoptosis is cell shrinkage. This is attributed to water loss, and hence implicates the membrane ion channels. The nuclear chromatin becomes aggregated in well-defined crescent-shaped clumps on the nuclear membrane. The cell membrane loses microvilli and becomes convoluted from both cell shrinkage around organelles and cytoskeletal reorganization (5). The convolution causes membrane blebbing that eventually leads to the budding off of apoptotic bodies. The apoptotic bodies usually contain one or a few organelles or condensed nuclear chromatin. Changes to the cell membrane of apoptotic cells apparently play a role in promoting phagocytosis of the apoptotic bodies by neighbouring cells. As well, these changes allow macrophages to phagocytose without apparent activation.

In mammalian cells, the molecular hallmark used today for the characterization of apoptosis is the nucleosomal ladder. Chromosomal DNA is degraded during apoptosis into single and multiple oligonucleosomes by cleavage in the internucleosomal linker region of the DNA. A calcium-dependent endonuclease is responsible for this specific cleavage. Electrophoretic separation of the DNA extracted from apoptotic cells show a characteristic banding pattern corresponding to fragments which are multiples of 180 to 200 base pairs, the length of the nucleosomes (6). However, caution must be exercised with this approach because apoptosis has been described in the absence of DNA laddering (7-9). Therefore, the nucleosomal ladder cannot be used as the sole criterion for apoptosis.

The entire process of apoptosis is very quick, with only minutes passing from the first visible signs to the formation of apoptotic bodies. However, phagocytosis of the apoptotic bodies may take up to $24 \mathrm{~h}$. The entire process, when occurring in vivo, leads to no release of inflammatory mediators and no induction of an inflammatory response.

Both apoptosis and necrosis lead to cell death. However, there are significant differences between these two types of 


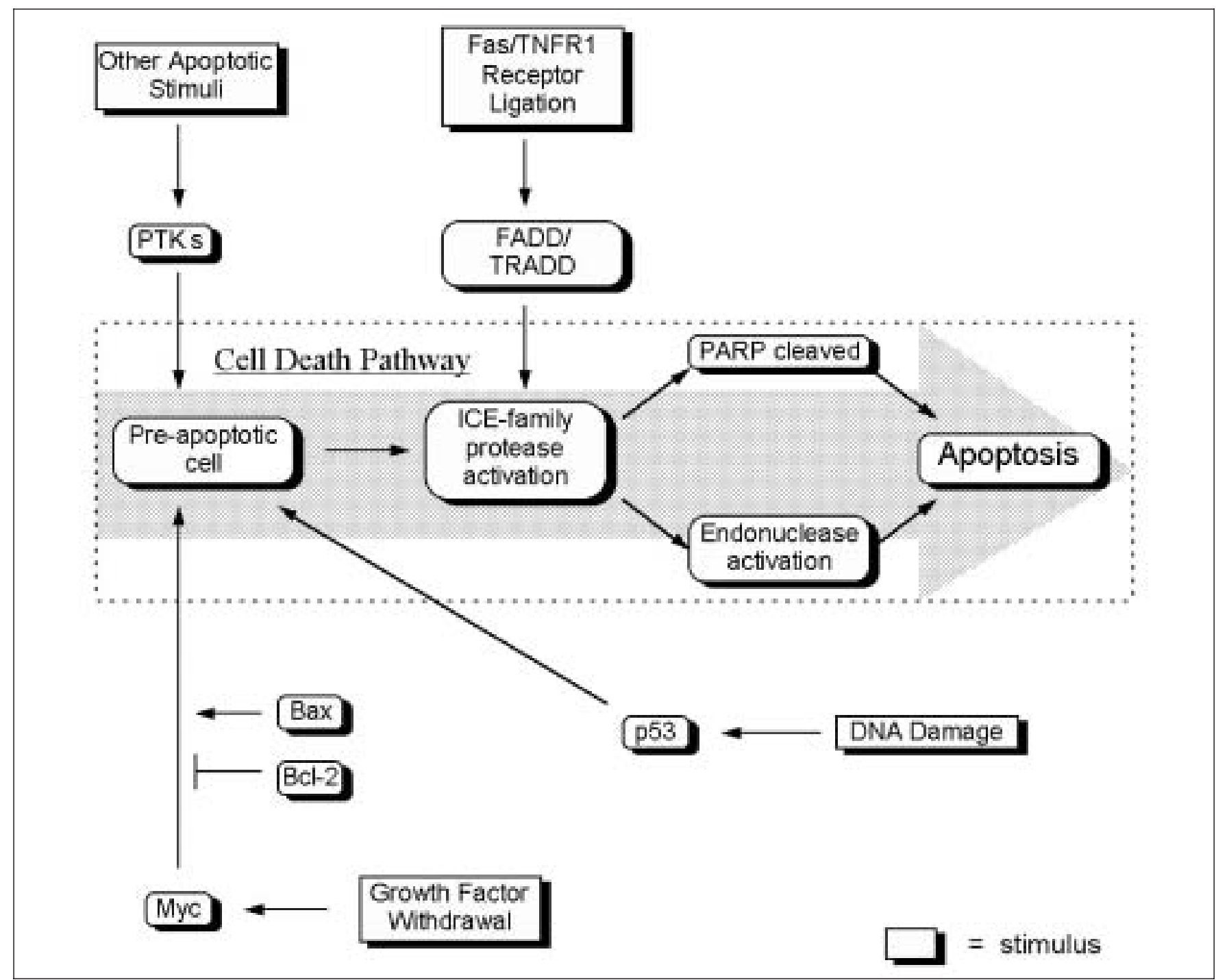

Figure 1) A schematic representation of some of the many events in cell death by apoptosis. Apoptosis may be triggered by a number of different stimuli. The initial stimuli, including growth factor withdrawal, DNA damage and other stimuli, signal using one of several pathways (eg, p53 for DNA damage, Myc for growth factor withdrawal, and certain protein tyrosine kinases [PTKS] for other stimuli). Certain stimuli such as Fas-ligand/Fas-receptor ligation can induce cell death by directly activating the cell death pathway through the interleukin-1 beta-converting enzyme (ICE)-family of proteases. Once the cell death program is initiated, a number of changes including poly (adenosine diphosphate-ribose) polymerase and endonuclease activation eventually cause cell death. PARP Poly(adenosine diphosphate-ribose) polymerase; TNFR1 Tumour necrosis factor receptor 1

cell death in terms of context, morphology and biochemistry. While apoptosis appears to be an innate process of virtually all cells of multicellular organisms and necessary for maintaining homeostasis, necrosis is a pathological form of cell death associated with an insult or injury to the cell. Necrosis is characterized by an initial cell swelling, indicating a loss of cell membrane function that results in increased permeability and intracellular edema. Nuclear chromatin breaks down into ill-defined clumps. Finally, organelle and lysosomal degradation cause cell lysis, releasing cytoplasmic and nuclear macromolecules and leading to an inflammatory response. In contrast, cells undergoing apoptosis retain membrane integrity, and inflammation is prevented. At the molecular level, the apoptotic process consists of the orderly implementation of the cell death program of biochemical events. It is, therefore, a biologically active process requiring protein synthesis $(6,10)$. An important characteristic of this is the specific DNA cleavage that occurs between nucleosomes. Necrosis, by contrast, is more an effect of injury than an actual orderly biochemical process. In necrosis, DNA cleavage and degradation is random.

\section{MOLECULAR MECHANISMS AND REGULATION}

While apoptosis is increasingly recognized as complementary to mitosis, used by organisms to remove unwanted, undesirable or redundant cells, very little is known about the basic biochemical processes and mechanisms of this form of cell death or its effect on the overall well-being of the organism. Much of the current knowledge of the molecular mechanisms and biochemistry of apoptosis stems from studies of the nematode Caenorhabditis elegans. C elegans is a very useful 
model system for the study of apoptosis because it has a very precise developmental pattern, with 131 of 1090 total cells undergoing apoptosis. Mutant nematodes have allowed the cell death pathways and the role of various genes important to apoptosis to be pieced together. These genes can be divided into several classes: those that are required for the induction of apoptosis, those required for carrying out the cell death program and those involved in the disintegration of the dead cells. This model of cell death has been found to translate well into mammalian systems. While the actual genes differ, a great number of the cell death genes in $C$ elegans have parallels in mammalian cells. In particular, the Ced-9 suppressor of apoptosis in $C$ elegans is homologous to the Bcl-2 family of proteins in mammalian cells, and the Ced-3 protein is homologous to the interleukin-1beta-converting enzyme (ICE) family of proteases. There are, as expected, some deficiencies in the model because certain parallels are absent (11).

A vastly simplified scheme of the current understanding of the molecular mechanisms, some triggering factors and regulatory components of the cell death pathway are depicted in Figure 1. It is now recognized that the cells of multicellular organisms require signals to remain alive. In the absence of these factors, most cells seem to initiate apoptosis by default. The factors involved and their modes of action are extremely diverse and differ among cell types. The induction of apoptosis can be brought about by either the removal of growth factors or the addition of some triggering factor. A combination of the two allows for precise control of the populations of cell types and allows for targeting of particular cells. Some fairly ubiquitous triggering factors include DNA damage, release of tumour necrosis factor (TNF) or glucocorticoids, and Fas/Apo-1 activation (12). Other triggering factors are more specific to the cell types involved, such as the deletion of immature thymocytes by binding of the T cell receptor (TCR) and death of macrophages following certain bacterial infections (13). Fas (also called CD95) is a receptor of the TNF receptor family. Fas-mediated apoptosis can be used by cytotoxic $\mathrm{T}$ lymphocytes and is also important for negative selection in $\mathrm{T}$ cell development. Another interesting triggering factor allows cells to detect changes in its extracellular structure and environment. For example, endothelial cells that lose contact with their extracellular matrix detect this via integrins and are induced to die by apoptosis.

A number of signal transduction pathways are used to communicate to the cell either a positive or negative signal for apoptosis. The pathways may be activated either through cell-surface receptors or through direct stimulation by agents which can traverse the cell membrane. Such signaling is usually context-dependent: intracellular signals involved in apoptosis are often also involved in differentiation and proliferation under different situations or conditions. In the case of the Fas/TNF receptor 1 (TNFR1) family of cell-surface receptors, ligation of certain members will promote cell survival, while ligation of others such as Fas and TNFR1 tends to cause apoptosis. The cell death signal in the case of Fas and TNFR1 is transduced by the activation of proteins associated with these receptors called FADD and TRADD, respectively.
These, in turn, function as adapter molecules linking the death signal downstream by causing the activation of various ICEfamily proteases, which activate other ICE-family proteases and finally result in apoptosis $(14,15)$.

The protease apopain and its proenzyme CPP32 have been recently identified and shown to be necessary for apoptosis, but are not sufficient to induce apoptosis (16). CPP32, unlike many proteases, is unable autocatalytically to cleave and activate itself into apopain. It requires the proteolytic activity of other proteases. Possible proteases include ICE, granzyme B (secreted by cytotoxic $\mathrm{T}$ cells to induce apoptosis in a target cell) and fragmentin-2 (secreted by natural killer cells. As mentioned earlier, ICE-family proteases are involved in Fas/TNFR1 family receptor-mediated apoptosis. After activation of CPP32 to apopain by other proteases, apopain cleaves several other cellular substrates. One that has been identified is poly(adenosine diphosphate-ribose) polymerase (PARP). PARP is involved in DNA repair and maintenance and its proteolytic inactivation by apopain has been shown to be an initial event in apoptosis.

One of the earliest changes observed after a cell is committed to death is an increase in the intracellular calcium levels $(17,18)$. Many cell-surface receptors signal through the $\mathrm{Ca}^{2+}$ pathway by activating phospholipase C (PLC). PLC hydrolyzes phosphatidylinositol 4,5-bisphosphate into inositol trisphosphate and diacylglycerol. Inositol trisphosphate causes an increase in calcium levels by opening calcium regulating channels in the endoplasmic reticulum and plasma membrane. Diacylglycerol exerts its effect by activating protein kinase $\mathrm{C}$ (PKC). However, because of crosstalk between different signaling pathways, PKC activation has been reported to both induce apoptosis and proliferation. Furthermore, many studies of PKC activation and apoptosis use inhibitors of PKC that may themselves induce apoptosis, thus complicating the interpretation of the studies' results.

Protein tyrosine kinases (PTK) are often the intermediate molecules involved in transducing either positive or negative signals for apoptosis from cell-surface receptors and cell-surface associated proteins to the nucleus. Certain cell-surface receptors possess intrinsic PTK activity, while others are associated with other proteins that are PTKs. A number of signaling pathways promoting cell survival involve PTKs; for example, activation of certain PTKs is required for growth factor promoted survival, and cells that overproduce some of the PTKs may become resistant to apoptosis induced by growth factor withdrawal (19).

Another important signalling pathway in apoptosis involves Ras, the GTPase that links upstream receptor and nonreceptor associated PTKs to downstream serine/threonine kinases. Ras is switched off by GTPase-activating proteins and is switched on by guanine nucleotide-releasing proteins. Activated Ras binds to and activates Raf, a serine/threonine kinase that activates other serine/threonine kinases. This cascade continues down to the mitogen-activated protein (MAP) kinases. The Ras/Raf/MAP kinase cascade appears to be involved in the inhibition of apoptosis, either directly or through the regulation of other apoptosis inhibitors (eg, Bcl-2) (20). 
The tumour repressor gene p53 is known to promote differentiation or apoptosis depending on the context and is one of the most common genes inactivated in human cancers. p53 is important, allowing cells to respond to DNA damage (eg, by irradiation) by causing growth arrest at the $\mathrm{G}_{1}$ phase. Cells with mutant p53 lack this checkpoint and arrest in $\mathrm{G}_{2}$ (21). This system allows the cell to assess the damage and to repair itself, if possible, or to undergo apoptosis if the DNA damage is too great. The ability of p53 to induce $G_{1}$ arrest following DNA damage lies in its function as a transcription factor. Increased levels of p53 following DNA damage upregulate a number of proteins that, in turn, inhibit cyclin-dependent kinases, causing cell cycle arrest. p53 appears to be necessary for the induction of apoptosis following DNA damage (22). However, p53-independent apoptosis also exists because certain cells in p53-deficient mice are resistant to radiation-induced apoptosis, but still undergo apoptosis in response to other stimuli.

A large number of oncogenes mediate and regulate apoptosis. A typical example of a transcription factor that is an oncogene affecting apoptosis is Myc. Myc is important in both cell proliferation and apoptosis. It interacts with the retinoblastoma protein ( $\mathrm{pRB}$ ), so that in the presence of certain growth-promoting cytokines, Myc can override the pRB-induced cell cycle arrest. However, during growth arrest (eg, during the absence of a growth factor), the presence of Myc induces p53-dependent apoptosis, which is suppressed by Bcl-2 (see below). Thus, overexpression of Myc acts as a two-way controlling mechanism that forces cells to either proliferate or die, depending on the immediate environment and presence of signals (23). Many viruses also produce oncoproteins that can act by binding to proteins that normally restrict cell growth, such as pRB (which controls cell cycle progression and suppresses apoptosis) or p53 (described below), or by suppressing apoptosis of the host cell, thus preventing the important immune defense mechanism of inducing apoptosis in virally infected cells.

Bcl-2 (first isolated from a B-cell lymphoma) has an inhibitory effect on apoptosis and was the first gene to be shown to regulate apoptosis (24). In adult organisms, $\mathrm{Bcl}-2$ is primarily expressed in tissues that are constantly renewed, are proliferative or are long-lived. Bcl-2 derives its oncogenic potential not from any inherent ability to induce proliferation, but rather by its ability to prevent apoptosis in cycling cells, and to promote the survival of noncycling cells, thus acting in conjunction with oncogenes like c-Myc, which can disregulate the cell cycle. Bcl-2 accomplishes these effects, in part, by forming high affinity heterodimers with Bax. Because Bax homodimers promote apoptosis (overexpression speeds apoptosis during growth factor withdrawal for some cells, but does not induce apoptosis in the presence of growth factor), either raising the transcription level of the Bax gene or decreasing the amount of Bcl-2 has the effect of increasing the susceptibility of the cell to apoptosis. The tumour suppressor p53 also plays a role because it is both a negative regulator of Bcl-2 expression and a transcription factor for the Bax gene (the Bax promotor has four p53 binding regions) $(25,26)$. The scope of Bcl-2 protec- tion against apoptosis appears quite large, including protection of many factor-dependent cells in $G_{0}$ until growth factor is restored; delay of p53-dependent apoptosis; resistance to killing by various chemotherapeutic agents; and blocking of apoptosis induced by glucocorticoids in immature lymphocytes. While much speculation about the exact mechanism of Bcl-2 action exists, little is known about how it actually prevents the induction of apoptosis.

\section{SIGNIFICANCE OF APOPTOSIS}

The significance of apoptosis is two-fold: first, it is essential for the normal health of multicellular organisms; and second, it has been implicated in both the pathogenesis and battle against many diseases.

From the earliest stages of the development of an organism, apoptosis plays a role in the maturation of tissues by altering their structure and function. During embryogenesis of humans, for example, the interdigital webs and other vestigial organs are removed by apoptosis. In the fetal lung, specific cells are programmed to die in order to enlarge the alveoli.

Throughout a human's life, cell turnover occurs in many locations in the body. The hemopoietic system constantly produces an enormous number of cells per day, which must be eliminated to maintain a constant level of blood cells. This is accomplished by apoptosis. Even neutrophils, which are packed with highly toxic chemicals, die by apoptosis. This indicates how inconspicuously apoptosis is integrated into the everyday existence of organisms. Tissue turnover also occurs on a variety of epithelial surfaces, including the skin and the intestinal lining (27). During the menstrual cycle, many types of cells proliferate and then must be eliminated. The process includes the shedding of the uterine lining and the turnover of mammary epithelial cells.

Apoptosis also plays a vital role in developmental immunology and host defense against certain viral infections. Both $B$ cell and T cell development and selection involve apoptosis. Cells that recognize self-antigens must be eliminated so that immune responses are not targeted to the body's own cells. During T cell maturation, cells differentiate into different types of $\mathrm{T}$ cells. One type, the activated effector $\mathrm{T}$ killer cells, uses apoptosis to kill virally infected cells. Cytotoxic T cells recognize viral antigens presented on the cell surface and signal to them (either by degranulation or by Fas activation) to undergo apoptosis.

The improper activation or the deactivation of apoptosis has been implicated in many disorders. It has been associated with the etiology of several neurodegenerative disorders, including Alzheimer's, Parkinson's and Huntington's diseases. As well, increased apoptosis has been associated with ischemic injury (28).

As one might expect, a sizable number of cancers have been shown to be caused not so much by an increase in growth and response to growth signals, but by a decrease in responsiveness to apoptotic signals, making cells less likely to die. For example, the B cell lymphoma from which Bcl-2 was first isolated, overexpressed Bcl-2, thus inhibiting apoptosis. Other tumours modify or suppress p53, making them resistant to 
death from DNA damage. This is an initial step allowing an otherwise normal cell to accumulate further mutations, and thus adapt readily for metastasis to other tissues.

A variety of viruses have been found that can modify the host cells' behaviour by expressing viral copies of some of the genes involved in apoptosis. For example, viruses such as the herpes viruses, pox viruses and adenoviruses encode apoptosis-inhibitors in their genomes $(29,30)$, increasing the probability that the host cells they infect will survive to produce more viral particles. It is by this mechanism that some viruses ultimately induce the formation of tumour cells in the infected host cells. A virus that acts not by inhibiting apoptosis, but by inducing it, is human immunodeficiency virus (HIV). Virally infected $\mathrm{CD} 4^{+} \mathrm{T}$ cells undergo activation-induced cell death (31). This contributes to the depletion of $\mathrm{CD}^{+}{ }^{+} \mathrm{T}$ cells during AIDS.

Apoptosis has also been implicated in many superantigen (sAg)-mediated diseases, such as staphylococcal and streptococcal toxic shock, certain autoimmune and neoplastic diseases, and both murine and human retroviral infections. While conventional antigens bind within the antigen-presenting groove of the major histocompatibility complex molecules and are recognized by TCR in that context, sAgs bind outside of the antigen-presenting groove and interact with the V-beta region of the TCR. SAgs bypass the normal selectivity of TCR and can stimulate entire V-beta subsets of the T cell repertoire present within the host organism. In the case of staphylococcal and group A streptococcal toxic shock syndrome, this causes a massive proliferation of the sAg-reactive $\mathrm{T}$ cells, along with a pronounced release of various pro-inflammatory cytokines. For staphylococcal toxic shock syndrome, several sAgs produced by Staphylococcus aureus, including toxic shock syndrome toxin-1 and staphylococcal enterotoxins A, B, $\mathrm{C}_{1}, \mathrm{C}_{2}, \mathrm{D}$ and $\mathrm{E}$, have been implicated as the primary cause of this illness. For streptococcal toxic shock syndrome, the streptococcal pyrogenic exotoxins A and $\mathrm{C}$ as well as several other sAgs produced by Streptocococcus pyrogenes are the major causes (32). Some other known sAg-producing microorganisms include Yersinia enterocolitica, Mycoplasma arthritidis and the mouse mammary tumour virus. While the most obvious effect of sAgs is the polyclonal proliferation of T cells, the

\section{REFERENCES}

1. Gregory CD. Apoptosis and the Immune Response. New York: Wiley-Liss, 1995.

2. Kerr JFR, Wyllie AH, Currie AR. Apoptosis: A basic biological phenomenon with wide-ranging implications in tissue kinetics. Br J Cancer 1972;26:239-57.

3. Wyllie AH, Kerr JFR, Currie AR. Cell death: The significance of apoptosis. Int Rev Cytol 1980;68:251-305.

4. Savill J. The innate immune system: Recognition of apoptotic cells. In: Gregory CD, ed. Apoptosis and the Immune Response. New York: Wiley-Liss, 1995:341.

5. Martin SJ, Green GR, Cotter TG. Dicing with death: dissecting the components of apoptosis machinery. Trends Biol Sciences 1994;19:26-30.

6. Wyllie AH, Morris RG, Smith AL, Dunlop D. Chromatin cleavage in apoptosis: Association with condensed chromatin morphology and dependence on macromolecular synthesis. J Pathol 1984;142:67.

7. Cohen GM, Sun XM, Snowden RT, Dinsdale D, Skilleter DN. Key morphological features of apoptosis may occur in the absence of other important effect of sAgs is apoptosis that appears to occur simultaneously, along with a downregulation of the TCR that results in anergy (33). The net result of these two contrary effects is to produce an initial rapid proliferation of sAg-reactive $\mathrm{T}$ cells, followed by either a profound deletion or anergy of these T cells. Therefore, while patients might survive staphylococcal or streptococcal toxic shock, they may still be in danger because of immunosuppression from the loss of up to $20 \%$ of their T cells. With viral sAgs, the picture is somewhat different. Instead, some viruses use sAgs to compel the host cells to proliferate, thereby promoting their own survival, replication and spread. In regard to HIV, there have been reports of Vbeta specific deletion of $\mathrm{CD} 4^{+} \mathrm{T}$ cells (34). This suggests that sAgs may be a cause of $\mathrm{CD}^{+} \mathrm{T}$ cell depletion in AIDS patients, with the sAg in question being either an unidentified HIV product, or more likely, a sAg from another pathogen that opportunistically coinfects the immunocompromised AIDS patient. Recently, evidence has also emerged to suggest that coinfection of host cells with cytomegalovirus may result in the expression of a herpes viral sAg that drives HIV replication preferentially in selected sAgresponsive $\mathrm{CD} 4^{+} \mathrm{V}$-beta12 $\mathrm{T}$ cell subsets (35). Hence, in AIDS retroviral sAgs may exert their effect primarily through inducing apoptosis and depleting HIV-infected $\mathrm{CD} 4^{+} \mathrm{T}$ cells, while sAgs from coexisting infections may actively promote HIV replication.

\section{CONCLUSION}

Within the past few years, apoptosis has been recognized to be fundamentally important in both the health and disease of multicellular organisms. Despite the enormous explosion of investigation in this area, little is known about the underlying mechanisms and pathways of apoptosis, and much of its regulation still remains a mystery. Future applications from an improved knowledge base of apoptosis include the possibility of treating many disorders and diseases by therapeutically altering the occurrence of apoptosis. As well, greater knowledge of apoptosis will improve the understanding of the complex balance that exists between life and death in multicellular organisms.

internucleosomal DNA fragmentation. Biochem ] 1992;286:331-4.

8. Tomei LD, Shapiro JP, Cope FO. Apoptosis in C3H/10T1/2 mouse embryonic cells: Evidence for internucleosomal DNA modification in the absence of double-strand cleavage. Proc Natl Acad Sci USA 1993;90:853-7.

9. Zakeri ZF, Quaglino D, Latham T, Lockshin RA. Delayed internucleosomal DNA fragmentation in programmed cell death. FASEB J 1993; 7:470-8.

10. Schwartzman RA. Cidlowski JA. Apoptosis: the biochemistry and molecular biology of programmed cell death. Endocrine Reviews 1993;14:133-51.

11. Yuan J. Molecular control of life and death. Curr Opin Cell Biol 1995; 7:211-4.

12. Cohen PL, Eisenberg RA. Fas/APO-1: A cell surface receptor that signals apoptosis. In: Gregory CD, ed. Apoptosis and the Immune Response. New York: Wiley-Liss, 1995:169.

13. Collins MKL, Lopez-Rivas A. The control of apoptosis in mammalian cells. Trends in Biochemical Sciences 1993;18:307-9. 
14. Chinnaiyan AM, O'Rouke K, Tewari M, Dixit VM. FADD, a novel death domain-containing protein, interacts with the death doamin of Fas and initiates apoptosis. Cell 1995;81:505-12.

15. Hsu HL, Xiong J, Goeddel DV. The TNF receptor 1-associated protein TRADD signals cell death and NFKB activation. Cell 1995;81:495-504.

16. Nicholson DW, Ali A, Thornberry NA, et al. Identification and inhibition of the ICE/Ced-3 protease necessary for mammalian apoptosis. Nature 1995;76:37-43.

17. Martin SJ, Green GR, Cotter TG. Dicing with death: dissecting the components of apoptosis machinery. Trends Biol Sci 1994;19:26-30.

18. Schwartzman RA, Cidlowski JA. Apoptosis: The biochemistry and molecular biology of programmed cell death. Endocr Rev 1993;14:133-51.

19. Evans CA, Owen-Lynch JP, Whetton AD, Dive C. Activation of the Abelson tyrosine kinase-activity is associated with suppression of apoptosis in hemopoetic cells. Cancer Res 1993;53:1735-8.

20. Wang HG, Miyashita T, Takayama S, et al. Apoptosis regulation by interaction of $\mathrm{Bcl}-2$ protein and Raf- 1 kinase. Oncogene 1994;9:2751-6.

21. Kuerbitz SJ, Plunkett BS, Walsh WV, Kastan MB. Wild-type p53 is a cell cycle checkpoint determinant following irradiation. Proc Natl Acad Sci USA 1992;89:7491-5.

22. Furuya Y, Berges R, Lundmo P, Isaacs, JT. Cell proliferation, p53 gene expression, and intracellular calcium in programmed death: Prostate Model. In: Tomei LD, Cope FO, eds. Apoptosis II: The Molecular Basis of Apoptosis in Disease. New York: Cold Spring Harbor Laboratory Press, 1994:231.

23. Bissonnette RP, Shi Y, Mahboubi A, Glynn JM, Green DR. c-myc and Apoptosis. In: Tomei LD, Cope FO, eds. Apoptosis II: The Molecular Basis of Apoptosis in Disease. New York: Cold Spring Harbor Laboratory Press, 1994:327.

24. Smith CA, Grimes EA, McCarthy NJ, Williams GT. Multiple gene regulation of apoptosis: Significance in immunology and oncology. In: Tomei LD, Cope FO, eds. Apoptosis II: The Molecular Basis of Apoptosis in Disease. New York: Cold Spring Harbor Laboratory Press, 1994:43.

25. Miyashita T, Harigai M, Hanada M, Reed JC. Identification of a p53-dependent negative response element in the Bcl-2 gene. Cancer Res 1994:54:3131-5.

26. Miyashita T, Reed JC. Tumor-suppressor p53 is a direct transcriptional activator of the human Bax gene. Cell 1995;80:293-9.

27. Budtz PE. Epidermal homeostasis: A new model that includes apoptosis. In: Tomei LD, Cope FO, eds. Apoptosis II: The Molecular Basis of Apoptosis in Disease. New York: Cold Spring Harbor Laboratory Press, 1994:165.

28. Thompson CB. Apoptosis in the pathogenesis and treatment of disease. Science 1995;267:1456-62.

29. Smith CA, Grimes EA, McCarthy NJ, Williams GT. Multiple gene regulation of apoptosis: significance in immunology and oncology. In: Tomei LD, Cope FO, eds. Apoptosis II: The Molecular Basis of Apoptosis in Disease. New York: Cold Spring Harbor Laboratory Press, 1994:43.

30. White E, Gooding LR. Regulation of apoptosis by human adenoviruses. In: Tomei LD, Cope FO, eds. Apoptosis II: The Molecular Basis of Apoptosis in Disease. New York: Cold Spring Harbor Laboratory Press, 1994:111.

31. Gougeon ML, Montagnier L. Apoptosis in peripheral T lymphocytes during HIV infection: Influence of superantigens and correlation with AIDS pathogenesis. In: Tomei LD, Cope FO, eds. Apoptosis II: The Molecular Basis of Apoptosis in Disease. New York: Cold Spring Harbor Laboratory Press, 1994:5.

32. Watanabe-Ohnishi R, Low DE, McGeer A, et al. Selective depletion of V $\beta$-bearing $\mathrm{T}$ cells in patients with severe invasive Group A streptococcal infections and Streptococcal Toxic Shock Syndrome. J Infect Dis 1995;171:74-84.

33. Miethke T, Wahl C, Heeg K, Wagner H. Superantigens: The paradox of T-cell activation versus inactivation. Int Arch Allergy Immunol 1995;106:3-7.

34. Posnett DN, Kabak S, Asch A, Hodtsev AS. HIV-1 replication in T cells dependent on TCR V $\beta$ expression. In: Huber BT, Palmer E, eds, Superantigens: A Pathogen's View of the Immune System. Plainview: Cold Spring Harbor Laboratory Press, 1993:139.

35. Posnett DN. CMV drives HIV replication in selected Vb subsets: Evidence for a herpes virus superantigen. National Symposium of Basic Aspects of Immunology. Bethesda, MD, May 1-3, 1996. (Abst) 


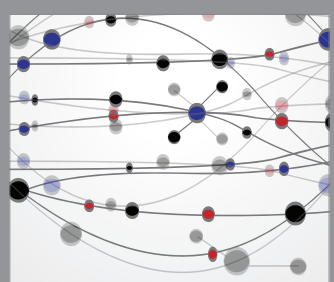

The Scientific World Journal
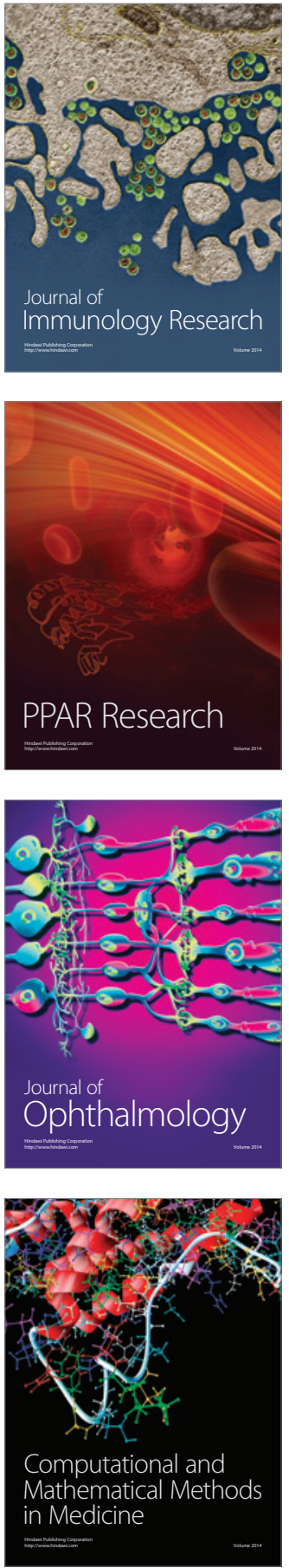

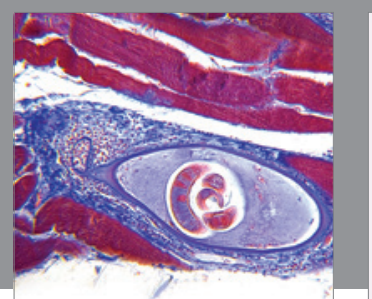

Gastroenterology Research and Practice

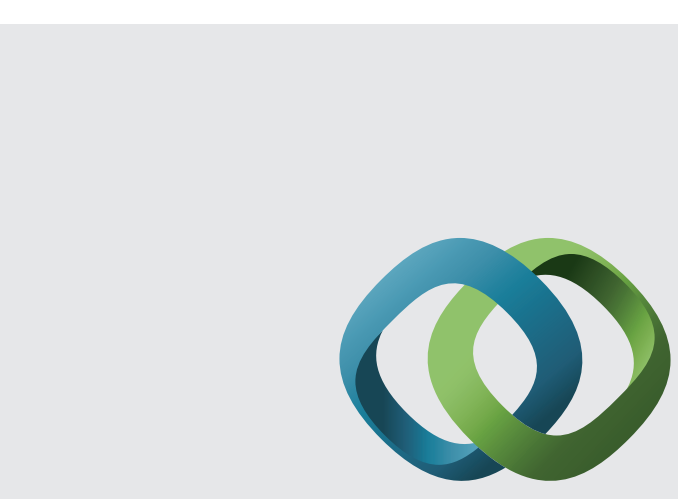

\section{Hindawi}

Submit your manuscripts at

http://www.hindawi.com
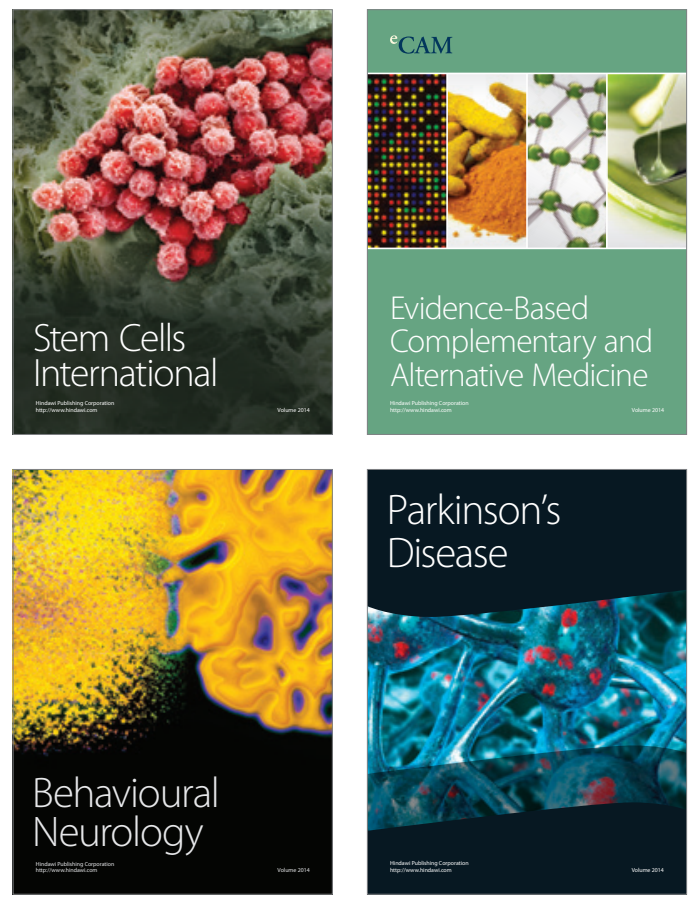
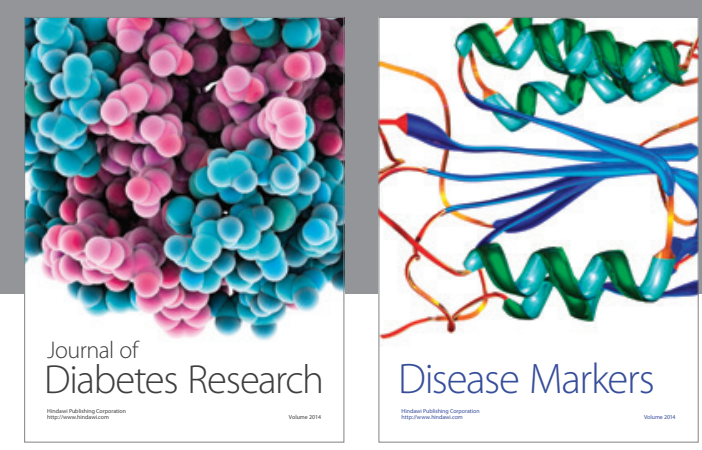

Disease Markers
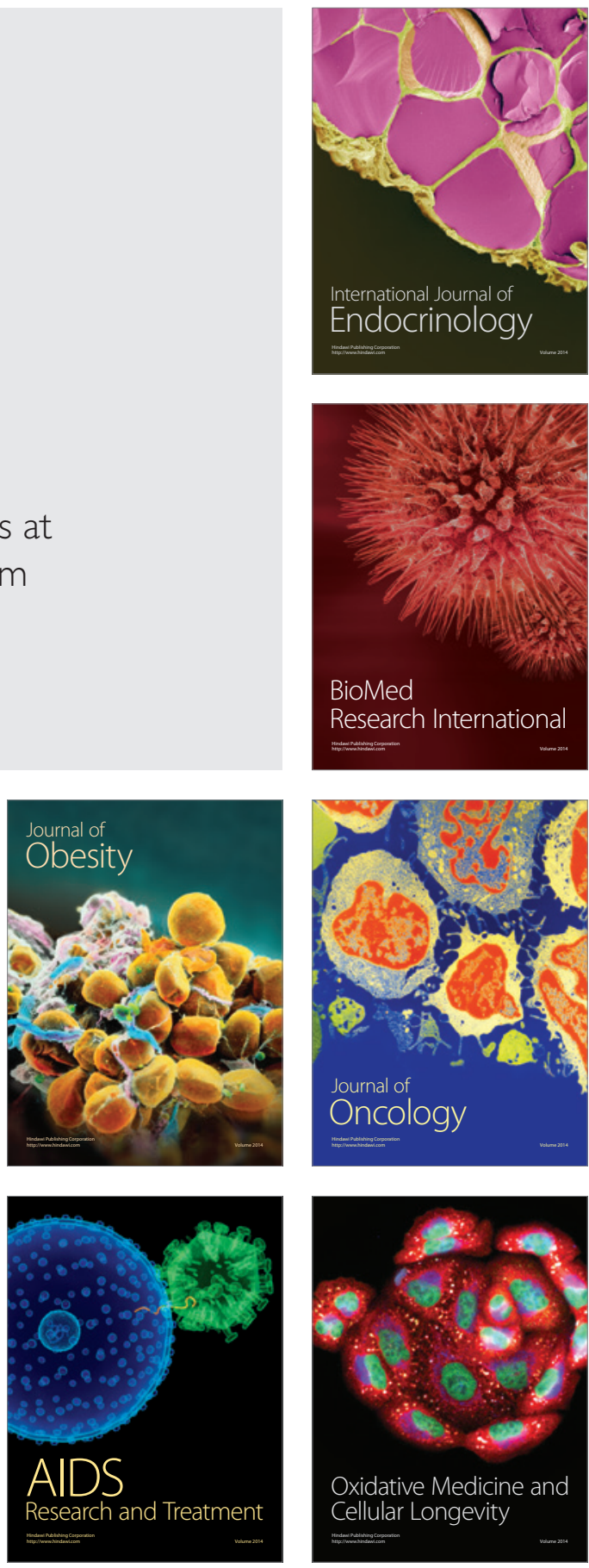